\title{
SENSORIAMENTO DA EDIFICAÇÃO: UM SISTEMA DE LOCALIZAÇÃO BASEADO EM BEACONS BLE ${ }^{1}$
}

\author{
SENSORING THE BUILDING: INDOOR POSITIONING SYSTEM BASED ON \\ BEACONS BLE
}

José Luis Menegotto

Universidade Federal do Rio de Janeiro (UFRJ) imenegotto@poli.ufri.br

\begin{abstract}
Resumo
No ano 2010 foram introduzidos os emissores Bluetooth de baixa energia (Bluetooth Low Energy). Desde então, eles vêm sendo utilizados no projeto de sistemas de localização indoor. Neste artigo, apresentamos o desenvolvimento de um aplicativo de localização baseado no uso de dispositivos emissores de sinais BLE, denominados beacons (balizas), associados a dispositivos móveis tipo smartphone que atuam como receptores e processadores dos dados transmitidos desde a baliza. O aplicativo visa fornecer uma ferramenta de localização espacial para as pessoas, além de ser uma ferramenta de suporte para os gestores dos recursos humanos e físicos da edificação. O sistema utiliza a especificação do protocolo e a biblioteca de funções AltBeacon. O aplicativo é preparado com uma interface gráfica que coexiste com uma interface de VUI (voice user interface) que envia avisos falados para o usuário do dispositivo receptor, indicando-lhe a sua localização espacial ou alertas da localização de objetos ou pessoas que possuam beacons associados. A infraestrutura de posicionamento é definida pela distribuição das balizas de acordo a um projeto de zoneamento dos espaços da edificação previamente definido. Será descrita a estrutura geral da infraestrutura necessária, a arquitetura do sistema, os resultados obtidos e algumas considerações acerca das possibilidades que a tecnologia oferece ao gerenciamento da infraestrutura edilícia.
\end{abstract}

Palavras-chave: Beacons BLE. Mobilidade assistida. Localização Indoor, Internet das coisas.

\begin{abstract}
Low energy Bluetooth transmitters (BLE) were introduced in 2010. Since then, Indoor Positioning Systems increased the repertoire of solutions. This article presents the development of an application based on the use of emitting BLE devices, generally called beacons, associated with mobile smartphone devices that act as receivers and processors of transmitted data. The application aims to provide a spatial localization tool for users in general as well as being a support tool for managing human and physical resources of the building. The system uses the specification of AltBeacon protocol and its C\# function library. The application is prepared with a graphical interface that coexists with a VUI interface (voice user interface) that sends spoken warnings to the user of the receiving device, showing their spatial location or alerting the location of objects and people. The positioning infrastructure is defined by the distribution of beacons according to a zoning project of the building rooms previously defined. It will be described the overall elements of the infrastructure, system architecture, results and some considerations about the possibilities that this technology offers to managing building data.
\end{abstract}

Keywords: Beacons BLE. Location-aided mobility. Indoor location, Internet of Things.

\footnotetext{
${ }^{1}$ MENEGOTTO, JOSE LUIS. Sensoriamento da edificação: um sistema de localização baseado em beacons BLE. In: ENCONTRO BRASILEIRO DE TECNOLOGIA DE INFORMAÇÃO E COMUNICAÇÃO NA CONSTRUÇÃO, 7. 2015, Recife. Anais. Porto Alegre: ANTAC, 2015.
} 


\section{중}

\section{INTRODUÇÃO}

Os sistemas de localização e microlocalização em ambientes fechados (Indoor Positioning System) têm sido programados utilizando diversas infraestruturas. Durante os últimos 15 anos, os pesquisadores desse campo vêm realizando esforços visando o aumento da precisão de inferência nos algoritmos de localização. Dentre os sistemas que foram propostos, alguns utilizam infraestruturas baseadas em emissores de rádio frequência (RADAR, Place Labs, Herecast, Ekahau, LandMarc, Moca); outros são baseados em sinais de ultrassom (Cricket Location System, Active Bat) e há ainda os que utilizam sinais infravermelhos (Active Badge Location System) (GU et al., 2009). De modo geral, pode-se dizer que os dispositivos móveis, como cartões magnéticos, PDAs, laptops, tablets e smartphones, são um dos elementos que integram a infraestrutura nas diversas soluções de localização indoor e que as técnicas de inferência adotadas evoluem em paralelo às funcionalidades desses dispositivos.

Em anos recentes, os smartphones foram equipados com funções específicas que permitem desenvolver sistemas para localizar usuários e objetos a partir de um leque de opções que incluem a tradicional leitura e triangulação de sinais de RF das redes $\mathrm{WiFi}$, até soluções combinadas, nas quais participam os acelerómetros e outros sensores presentes no aparelho. Apesar dessas possibilidades, alguns pesquisadores têm observado que a localização em ambientes fechados ainda não tem sido adotada em grande escala. Em Lamarca (2005), encontramos apontadas algumas das causas. $\mathrm{Na}$ opinião desses autores, algumas dificuldades impedem que a localização indoor seja mais difundida, justamente nos locais onde mais presentes estamos e onde os sistemas baseados em GPS oferecem um método de localização impreciso. Eles apontam os seguintes fatores: alto custo inicial da infraestrutura necessária; a calibração demorada dos sistemas; a escassez de aplicativos; e, as poucas encomendas de sistemas sob medida (LAMARCA et al., 2005).

A elevada taxa de consumo de energia das baterias dos aparelhos, necessária para manter ativos os processos de localização, também pode ser apontada como um dos pontos críticos dos métodos clássicos, tanto em ambientes externos, através do uso de GPS, como nos ambientes fechados através da leitura de sinais RF emitidos pelos pontos de acesso das redes WiFi.

Mais recentemente, no ano 2010, surgiu uma tecnologia de emissão de sinais de rádio frequência que possibilita a emissão e recepção de sinais consumindo baixas quantidades de energia. Trata-se da tecnologia denominada Bluetooth Smart, Bluetooth Low Energy ou Bluetooth 4.0, que permite projetar dispositivos de emissão BT que podem ser alimentados por fontes de energia como as pequenas baterias de 3V CR 2032. O Bluetooth Smart possibilitou o desenvolvimento de emissores pequenos e econômicos que, desde então, vêm ocupando um espaço maior no projeto de sistemas de localização indoor alternativos.

Como indicam os desenvolvedores dessa tecnologia, uma das características que diferencia o bluetooth tradicional do bluetooth BLE é que a conexão entre os dispositivos não precisa ser realizada através de pareamento, o que permite a descoberta passiva e contínua de dispositivos e aplicativos (SMART CARD ALLIANCE MOBILE AND NFC COUNCIL, 2015). A interoperabilidade entre fornecedores e a possibilidade de ampliar o rádio de alcance são outras características que tornam o BLE atrativo em relação ao BT tradicional (BLUETOOTH DEVELOPER PORTAL, 2015). Assim, a tecnologia BLE vem se inserindo como uma alternativa adicional para os sistemas de localização. Ela permite o desenvolvimento de aplicativos que ajudem a gerenciar dinamicamente dados contextuais. Na prática, exemplos de sua aplicação podem ser encontrados em situações onde seja útil rastrear, de forma dinâmica, recursos humanos e físicos, verificando e fornecendo informações de contexto em tempo real. Como contexto entende-se um modo de indicar o conjunto de dados que descrevem a identidade, o estado, a atividade e a forma de interagir que caracterizam usuários e objetos numa determinada situação espaço temporal. 
Algumas experiências já começaram a ser testadas. Um campo de desenvolvimento onde as possibilidades abertas pelos dispositivos Bluetooth Smart estão sendo introduzidas e exploradas é o desenvolvimento de aplicativos de mobilidade assistida, dirigida para pessoas portadoras de deficiência visual. Experiências realizadas nesse sentido estão sendo testadas na cidade de Budapest, através do sensoriamento dos pontos de ónibus e dos veículos. $O$ sistema testado funciona como um assistente de embarque, cuja função é a de informar aos passageiros com deficiência visual a qual linha de ónibus pertence o veículo que está se aproximando do ponto em que eles aguardam (SUPEALA, 2015).

De modo geral, diversos serviços podem ser programados a medida, com o intuito de fornecer informações de contexto para a população permanente ou temporária de edificações ou entornos urbanos. As bases de dados gerenciais contendo os recursos alocados em edificações podem ser integradas aos sistemas de localização e seguimento, visando a funcionar como assistentes para as operações de manutenção programada nas edificações que exigem ter um alto grau de comprometimento no seu controle operacional, como os grandes centros comerciais, museus, centros de saúde, escolas, universidades e centros administrativos.

\section{INFRAESTRUTURA DO SISTEMA}

A seguir são apresentados os elementos de um aplicativo para microlocalização Indoor baseado no uso de dispositivos móveis tipo smartphone associados a emissores BLE. Os smartphones atuam como receptores de sinais RF, emitidos por dispositivos Bluetooth BLE denominados beacons ou, em português, balizas. Beacons emissores de sinais RFID (Radio Frequency Identification) já foram utilizados em sistemas de localização como o LandMarc e Ekahau (NI et al., 2004).

A localização espacial proposta utiliza a instalação de uma malha de beacons dedicados. A distribuição física dos beacons nos compartimentos da edificação é acompanhada por uma base de dados em formato XML que funciona como mapa de referências dos serviços projetados. Nos referiremos à primeira como a infraestrutura física e à segunda como a infraestrutura lógica.

Figura 1 - Beacons utilizados na experiência

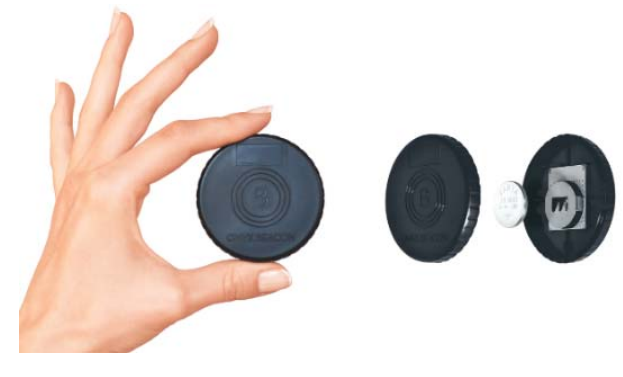

Fonte: OnixBeacon, 2015

\subsection{Infraestrutura física: posicionamento dos beacons}

Como a localização é baseada na transmissão e recepção de dados através da captação e filtragem de sinais de rádio frequência (RF), a distribuição de balizas nos espaços sensorizados é um aspecto que merece atenção, pois o sinal é afetado pelos obstáculos que se interpõem entre o emissor e receptor o que acaba por afetar a precisão das medições.

Outro aspecto que deve ser levado em conta são as divergências entre o momento de calibração do sistema e o momento do seu uso real. Como aponta Lymberopoulos (2015), 
entre o momento da calibração de um sistema de localização indoor e o momento da medição real, podem ser verificadas divergências de precisão na ordem dos $3 \mathrm{~m}$. Tal divergência, pode ser ocasionada pelas mudanças realizadas no mobiliário, pela diferença no deslocamento de pessoas ou por interferências de outros sinais (LYMBEROPOULOS et al., 2015). Portanto, neste trabalho, um dos problemas que está sendo observado com atenção diz respeito à influência que tem a característica da distribuição geométrica dos espaços da edificação sobre a precisão de inferência do sistema. As observações visam a entender de que modo a distribuição geométrica ou a dinâmica interna e funcional dos espaços atuam sobre a precisão do sistema de localização.

Os testes estão sendo realizados em duas edificações que possuem configurações espaciais e escalas diferentes. Procurando entender o grau de influência que a geometria da malha de beacons teria sobre a inferência de localização, estão sendo testadas algumas configurações em ambos os prédios estudados.

Num dos edifícios, que alberga funções educativas, escolheu-se como área de estudo um setor de $260 \mathrm{~m}^{2}$. Os beacons foram instalados aderidos aos vãos das portas e adjacentes às aduelas ou aberturas dos cômodos, em alturas de $2.00 \mathrm{~m}$ a $2.10 \mathrm{~m}$. Dois critérios nortearam o posicionamento dos beacons: em primeiro lugar, eles foram instalados em lugares que estão acima da altura da maioria dos usuários. O outro critério foi o de respeitar a configuração lineal da distribuição dos compartimentos.

Figura 2 - Posicionamento dos beacons prédio A.

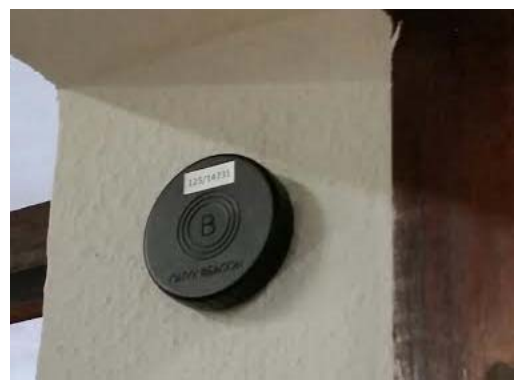

Fonte: O autor, 2015

Duas configurações de balizas foram testadas. Inicialmente, instalaram-se cinco balizas distanciadas entre si a $5.00 \mathrm{~m}$ e $7.50 \mathrm{~m}$. Mais tarde, alterou-se a densidade da malha diminuindo a quantidade de balizas para três, separadas entre si a 10.00 m (Figura 3).

Figura 3 - Distribuição de beacons prédio A.

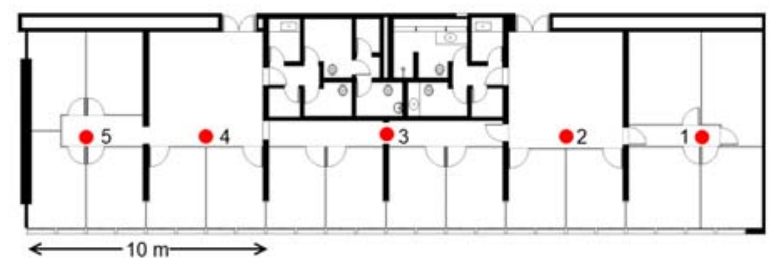

Prédio A: configuração 1

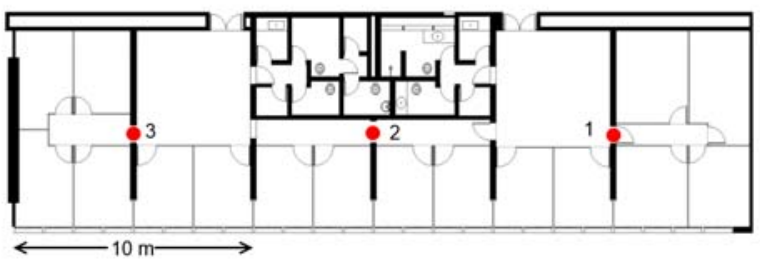

Prédio A: configuração 2

Fonte: O autor, 2015

O segundo local de estudo foi definido dentro de uma unidade residencial. A rede de beacons foi estabelecida posicionando-os no teto dos cómodos secos, na região central do compartimento ou próxima a ela. Nessa configuração, a distância entre balizas está na ordem dos 3.50 metros (Figura 4, prédio B). 
Figura 4 - Distribuição de beacons prédio B.

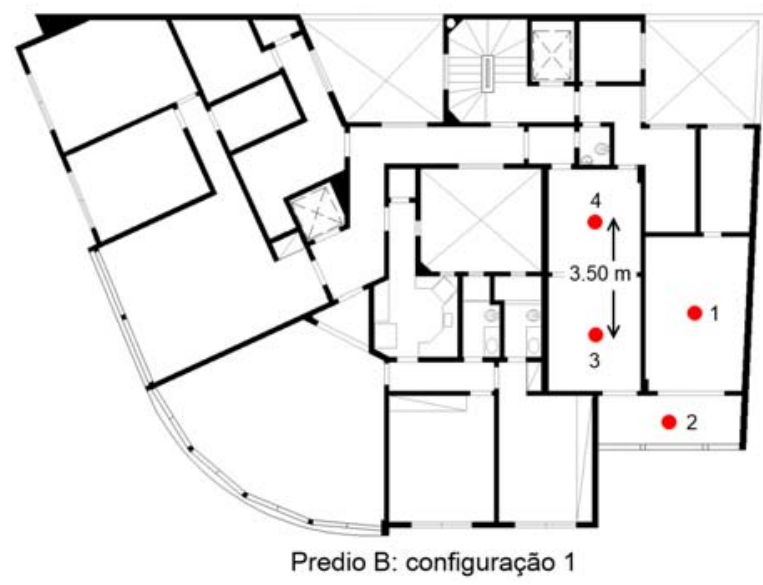

Fonte: O autor, 2015

\subsection{Infraestrutura lógica: grafo de continuidades}

A cada posição da rede de beacons lhe é assignado um número inteiro cujo valor dependerá da numeração dos cômodos adjacentes que podem ser acessados diretamente e sem obstáculos a partir dessa posição. O objetivo é configurar uma malha contínua e ordenada de nodos numerados que permita ao mecanismo de inferência de localização levar um controle do movimento efetuado pelo usuário e tomar decisões baseado nessa informação. $O$ movimento é registrado numa matriz de três elementos, cujo objetivo é armazenar a última posição captada e poder compará-la com os movimentos válidos possíveis a partir desse nodo. Na figura 5 , as setas vermelhas indicam movimentos não válidos.

Como não faz sentido passar da posição de um local de numeração $n$ para um local $n+2$ ou $n-2$ sem antes passar pelo $n+1$ ou $n-1$ a matriz tem a seguinte configuração [ $n-1, n, n+1]$. Nela, o valor central $(n)$ registra o número da posição da leitura atual. Os valores extremos $(n-1$ e $n+1$ ) são as posições de localização válidas e possíveis para a próxima leitura.

Figura 5 - Exemplo de numeração dos nodos.
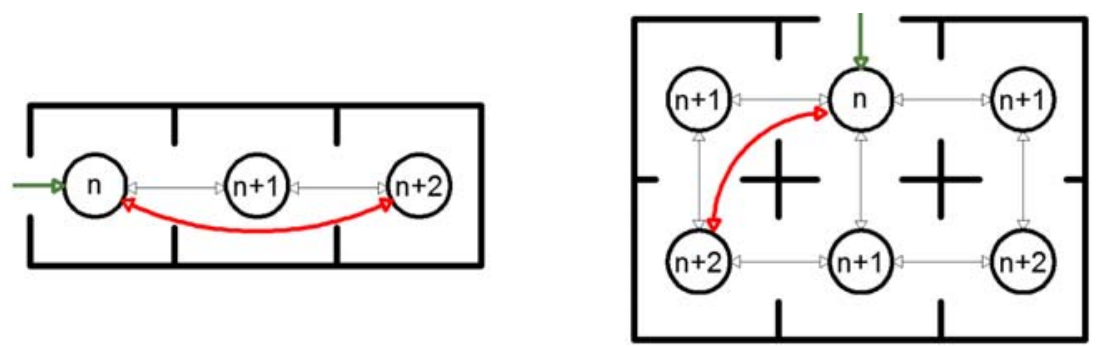

Fonte: O autor, 2015

\subsection{Infraestrutura lógica: mapa de referências}

O aplicativo foi programado em linguagem C\# no ambiente de desenvolvimento Xamarin. É utilizada a biblioteca de funções disponibilizada pela organização AltBeacon. O sistema foi testado em dispositivo Samsung Galaxy S5 com sistema operacional Android 4.4.2 e, mais recentemente, foi atualizado para Android 5.0. A biblioteca de funções da AltBeacon é declarada no código: 
AltBeacon é um protocolo de envio de mensagens contextuais desde o beacon. Os dados transmitidos são organizados numa corrente de caracteres que é recebida pelo aplicativo instalado no telefone. Esses dados são utilizados para disparar os serviços de ações e processos especificamente programados e que são úteis para o usuário ou gestor. A estrutura da corrente de caracteres é analisada de acordo à seguinte especificação do protocolo.

$$
\text { Estrutura.SetBeaconLayout("m:2-3=0215,i:4-19,i:20-21,i:22-23,p:24-24"); }
$$

Nessa corrente estão expressos um identificador universal UUID, um código numérico de zona (Major) e um código numérico de local (Minor).

\section{fb0b57a2-8228-44 cd-913a-94a122ba1206 Major 1 Minor 2}

A representação lógica da organização espacial da infraestrutura de balizas adotada (identificadores e numerações) permanece estruturada em arquivo XML. Esse arquivo é armazenado em um servidor Web. Ao iniciar o processo de localização, o aplicativo faz a leitura do conteúdo do mapa no servidor de Internet e transfere esses dados espaciais para o dispositivo móvel, que a partir desse momento passa acessá-los de modo local, evitando assim os atrasos da comunicação com o servidor Web. Essa estratégia visa manter a velocidade de resposta do processo.

A interface gráfica do aplicativo apresenta uma imagem em formato PNG com a planta baixa do setor sensorizado da edificação. Na estrutura do arquivo XML são cadastradas as coordenadas $x y$ do pixel do bitmap correspondente ao centro de cada compartimento ou zona sensorizada. $\mathrm{O}$ cadastro é realizado em forma de atributo $x$ e $y$ do elemento $\mathrm{XML}<$ Beacon $>$.

Figura 6 - Estrutura XML: elemento beacon.

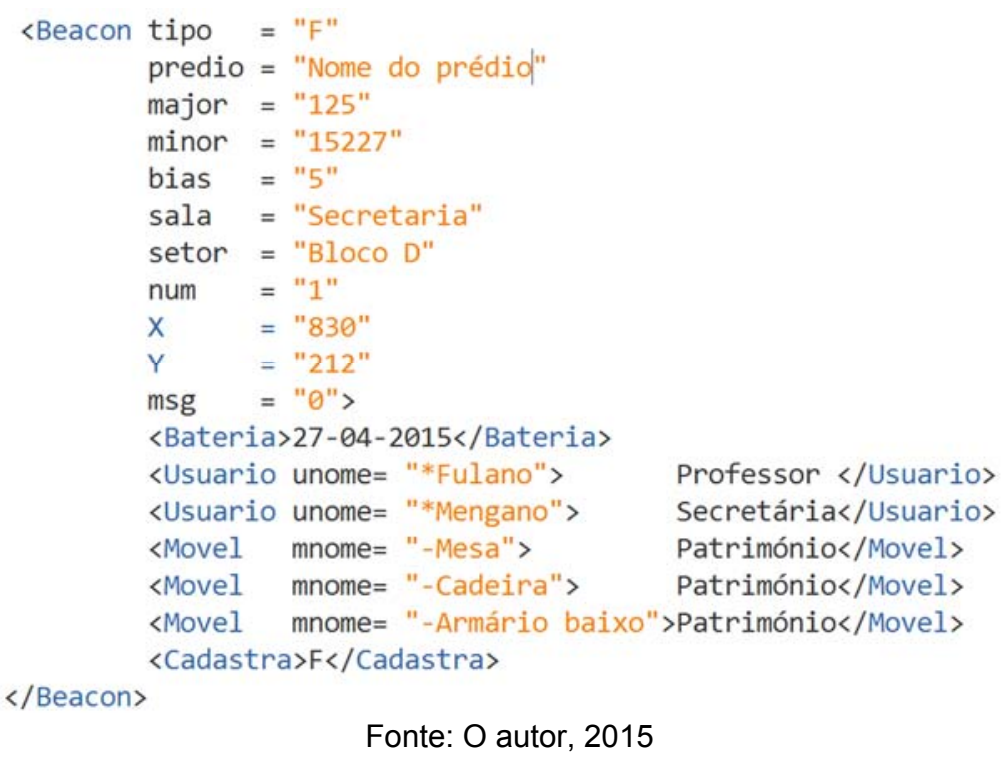

$$
\text { Fonte: O autor, } 2015
$$

A função dessa coordenada é fornecer ao usuário a referência visual do local encontrado no mapa. Os beacons foram definidos como o principal elemento XML, contendo a definição de alguns atributos associados a ele.

Procura-se ampliar a cobertura de sinal tentando não deixar zonas com sombras de sinais. $O$ aplicativo foi programado para receber o sinal transmitido pelo beacon com intervalos regulares de 125 milissegundos. 


\subsection{Camadas do sistema}

Na primeira versão do projeto, os beacons foram divididos em duas categorias:

- Beacons fixos

- Beacons móveis.

A função da camada de beacons fixos (distribuídos segundo figuras 3 e 4) é a de fornecer a identificação simbólica dos espaços. O sistema associa o valor numérico do local (código Minor) a um compartimento específico. Esse atributo é utilizado como chave para encontrar os elementos associados na base de dados.

A camada de beacons móveis é definida para fornecer a identificação de recursos que se movimentam livremente dentro da edificação (pessoas, equipamentos, produtos ou veículos em geral). Os beacons são posicionados aderidos ou carregados por esses recursos. Se comparados com os sistemas tradicionais, os beacons móveis funcionariam como os cartões tags. Em etapas futuras, planeja-se dividir a camada móvel em novas categorias de elementos incorporando novos atributos ao arquivo XML.

\subsection{A interface}

O aplicativo foi programado para funcionar com uma interface GUI (Graphical User Interface) coexistindo a uma interface VUI (Voice User Interface). O modo gráfico tem o intuito de fornecer informações relativas às leituras realizadas, fornecendo para o usuário uma referência espacial bidimensional do contexto localizado, assim como os registros fotográficos dos recursos humanos e físicos associados a esse contexto.

Figura 7 - Interface gráfica em dispositivo Galaxy S5 com Android 5.0.
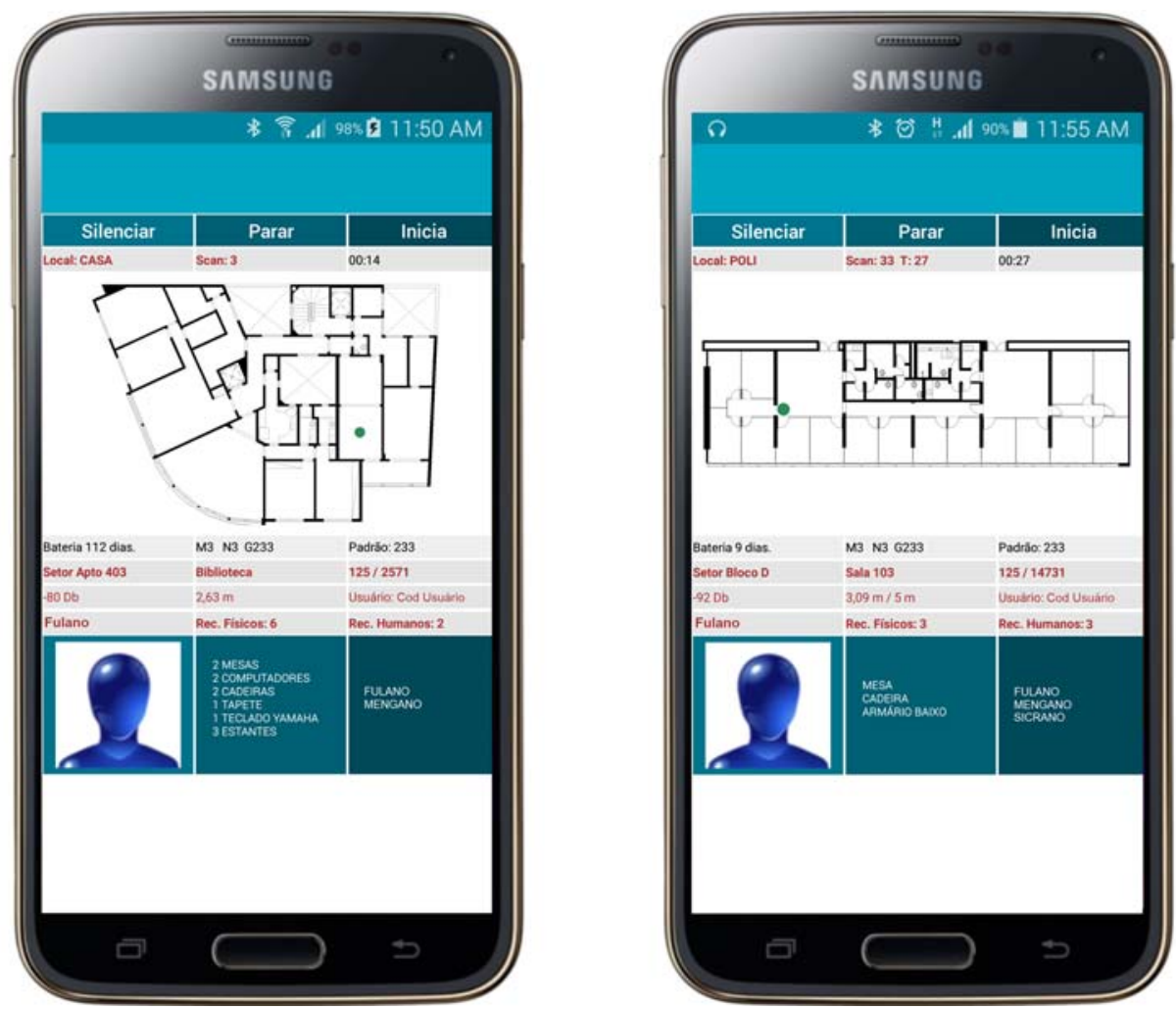

Fonte: o autor, 2015 
A tecnologia BLE permite energizar os beacons com baterias CR2032. Segundo os fabricantes de diversos modelos, a duração média das baterias pode chegar até um ano ou mais. Para verificar o tempo de autonomia das baterias preparou-se um campo na interface que apresenta a informação do tempo de uso real da bateria. A data de substituição da bateria é um campo registrado no mapa XML. A interface por voz procura ser um recurso complementar à interface gráfica, além de funcionar como a interface principal para as pessoas portadoras de deficiência visual que utilizam o aplicativo. As mensagens com informações de contexto procuram servir principalmente, mas não de modo exclusivo, como assistentes de orientação de usuários portadores de deficiência visual. Esse aspecto do aplicativo está em face de preparação e o seu uso fora do laboratório será objeto de análise em fases posteriores.

\section{RESULTADOS OBTIDOS}

O algoritmo de inferência da localização foi analisado em várias etapas. Inicialmente, programou-se o mecanismo ordenando apenas a lista de intensidades de sinais captados medidos em decibéis RSSI (Received Signal Strength Indicator), sem adicionar nenhum tipo de filtro. Em teoria, a baliza mais próxima ao dispositivo receptor tem a força mais intensa e os sinais enfraqueceriam na medida em que o receptor fica mais distante. No entanto, por causa das flutuações dos sinais, o ordenamento das forças pode não corresponder às distâncias reais. Locais em fronteiras equidistantes às balizas, também configuram uma fonte de leituras problemáticas e não confiáveis. Funcionando apenas como um sistema de captação e resposta, a inferência de localização a partir de leituras não filtradas variaram com taxas de acertos que estão entre $50 \%$ a $60 \%$. Os testes foram realizados no Prédio B (configuração 1) com o aparelho imóvel posicionado em uma região central do espaço embaixo do beacon $n^{\circ} 3$. Para controlar e verificar o resultado, para cada teste foram cadastrados em arquivo texto externo os dados obtidos de 100 leituras simultâneas.

Como a leitura da força do sinal RSSI sofre variações que dependem de diversos fatores como os já descritos (obstáculos, interferências, movimentos, etc.), colocaram-se filtros no algoritmo com vistas a melhorar a precisão de inferência da localização no aparelho. Um filtro testado foi o controle das leituras através dos dados gravados no grafo de continuidades. A matriz de continuidade $[n-1, n, n+1]$ é utilizada para inibir os avisos da interface sempre que as leituras realizadas pulassem mais de uma posição. Por exemplo, detectar a posição correspondente ao beacon 4 depois de ter detectado uma posição no beacon 2. Para uma posição qualquer $n$, as posições válidas seguintes são as que estão registradas na matriz, ou seja $n-1, n$ ou $n+1$. Esses valores podem ser interpretados como um movimento de retorno à posição anterior, uma parada na posição atual ou um movimento de avanço para o próximo nodo. Essa estratégia mostrou-se efetiva quando o movimento de deslocamento se dá com uma velocidade de passo cadenciado ou lento. Ainda resta, no entanto, programar funções que resolvam os problemas relacionados com as velocidades de deslocamento, uma vez que a resposta do sistema pode ser mais demorada que a velocidade do deslocamento de um usuário andando a passo acelerado.

Para tentar aumentar a taxa de acertos na inferência, se utilizou a técnica da continuidade reforçada por um segundo filtro, que diz respeito à distância entre o beacon e o dispositivo móvel. Novamente, um dos dados do sistema é a leitura do sinal de rádio frequência em decibéis e uma distância estimada a partir dessa medição. A distância é um dado calculado e retornado automaticamente como parâmetro pelas funções da biblioteca AltBeacon. Verificouse que o dado calculado não corresponde com a distância real. Depois de realizar diversas medições e comparações, calibrou-se esse valor com um fator de correção. Esse fator 
numérico pode ser apontado como um dos valores que devem ser verificados e ajustados quando o sistema for instalado em contextos espaciais diferentes.

Além do fator de correção, estipulou-se uma dimensão de tolerância espacial, fora da qual as leituras são descartadas. No caso do prédio educacional (prédio A), a distância de tolerância foi estabelecida em 5 metros, que é o módulo espacial comum às zonas mapeadas. Para o contexto residencial, foi estipulado um módulo de tolerância de 3 metros, que é o módulo espacial da largura dos cômodos. O valor do módulo de tolerância é cadastrado no atributo bias no mapa XML. Cada beacon pode ser configurado com uma tolerância independente o que permite ajustar as tolerâncias para as diversas situações. Inclusive com distâncias menores a 1 metro. Com a participação de todos os filtros programados elevaram-se as taxas de acerto de inferência para valores próximos a $90 \%$.

\section{CONCLUSÕES}

Para sensorizar um prédio com a infraestrutura adotada nesta experiência e considerando-se apenas a camada fixa de beacons, podem-se definir serviços de localização estimando uma densidade de malha na ordem dos $100 \mathrm{~m}^{2} /$ beacon. Essa densidade permite obter uma cobertura com uma precisão de inferência de 3.0 a 5.0 m lineares e, respectivamente, uma precisão superficial de $36.00 \mathrm{~m}^{2}$ a $100.00 \mathrm{~m}^{2}$.

Assim, para sensorizar uma edificação de grande porte como é o caso do prédio educacional estudado (prédio A), cuja área bruta coberta por andar chega a ser de aproximadamente $110.000 \mathrm{~m}^{2}$, seria necessário utilizar uma quantidade de 1.100 beacons, posicionados estrategicamente num dos andares de modo a se cobrir a totalidade da área, evitando-se lugares com sombra do sinal. Isso significa um desafio para as operações de manutenção programada, uma vez que para não ter interrupções dos serviços de localização, as baterias teriam de ser substituídas com frequência anual (duração declarada por diversos fabricantes de beacons). Alguns fabricantes disponibilizam adaptadores de tomadas para plugar os beacons à rede elétrica e eliminar a necessidade de bateria. O inconveniente nesse caso, relaciona-se com o projeto geométrico de distribuição de beacons, pois este torna-se dependente do projeto geométrico de distribuição das tomadas e pontos de energia. Com relação à precisão do sistema, acreditamos que aumentando a quantidade de beacons distribuídos nos compartimentos, ajustando os filtros e os valores do módulo de tolerância possa ser melhorada a precisão de inferência para a distância de 1 metro. Nesse caso, junto com o aumento da quantidade de beacons, aumentaria o desafio de manter a malha em funcionamento ao longo do tempo.

Apesar dos beacons serem de fácil instalação e manuseio, a necessidade de troca periódica da bateria configura-se como um problema em edifícios de grande porte. Durante o transcurso da experiência imaginou-se que seria interessante poder contar com beacons BLE que sejam diretamente associados à rede elétrica, mas ao invés de serem plugados nas tomadas utilizando adaptadores específicos, como os oferecidos por alguns dos fabricantes, eles poderiam ser embutidos em lâmpadas ou luminárias. Acreditamos que os elementos de iluminação artificial, que se distribuem naturalmente pelo espaço arquitetônico, situando-se em geral nas regiões altas dos cômodos, tanto pela região periférica como nos centros, distribuídos regularmente ou concentrados, parecem ser o sócio ideal para a rede de beacons dedicados. Tal associação, evitaria a necessidade de repor as baterias, permitindo que o projeto de sensoriamento, com vistas à manutenção programada dos recursos edilícios, possa ser desenvolvido integrado à etapa de concepção do projeto arquitetônico.

Outra possibilidade, que não foi encontrada durante a pesquisa de modelos de beacons BLE, seria associar o emissor Bluetooth dentro de um conjunto com bateria e dispositivo de alimentação de energia com célula fotovoltaica. Essa associação prolongaria a autonomia dos 
beacons, uma vez que estariam equipados com baterias auto carregáveis, mantendo-os autônomos da rede elétrica. Isso permitiria expandir o uso da infraestrutura de microlocalização para locais externos, levando novos serviços de localização e de mobilidade assistida para contextos urbanos e rurais. Apontamos essa integração de dispositivos como potenciais linhas de pesquisa e desenvolvimento.

\section{REFERÊNCIAS}

LYMBEROPOULOS, D., LIU, J., YANG, X., CHOUDHURY, R. R., HANDZISKI, V., SEN, S. A Realistic Evaluation and Comparison of Indoor Location Technologies: Experiences and Lessons Learned. ACM SIGMOBILE Mobile Computing and Communications Review. Vol. 18. Issue 4. Oct. 2014. ACM, New York, NY, USA, 2014.

MUÑOZ-ORGANERO, M., MUÑOZ-MERINO, P. J., DELGADO K.C. Using Bluetooth to Implement a Pervasive Indoor Positioning System with Minimal Requirements at the Application Level.

BRUNO, R. \& DELMASTRO, F. Design and Analysis of a Bluetooth-based Indoor Localization System. Personal Wireless Communications, Lecture Notes. Computer Science. 2003.

GU, Y., LO, A., NIEMEGEERS, I. A Survey of Indoor Positioning Systems for Wireless Personal Networks. IEEE Communications Surveys \& Tutorials. Vol. 11, № 1. Pg.13 - 32. IEEE. 2009.

ANDERSSON, M. Use case possibilities with Bluetooth low energy in loT applications. White Paper. Disponível em <www.u-blox.com>acessado em 28 de abril 2015.

LAMARCA, A., CHAWATHE, Y., CONSOLVO, S. HIGHTOWER, J. SMITH, I. SCOTT, J. SOHN, T. HOWARD, J., HUGHES, J. POTTER, F., TABERT, J., POWLEDGE, P., BORRIELLO, G. SCHILIT, B. Place Lab: Device Positioning Using Radio Beacons in the Wild. Em: Proceedings of the $3^{\circ}$ International Conference on Pervasive Computing. May 2005.

NI, L. M., LIU, Y. LAU, Y.C. PATIL, A. P. LANDMARC: Indoor Location Sensing Using Active RFID. Wireless Networks. Vol 10. Issue 6. Pg. 701-710. Kluwer Academic Publishers, 2004.

SMART CARD ALLIANCE MOBILE AND NFC COUNCIL. Bluetooth Low Energy (BLE) 101: $\boldsymbol{A}$ Technology Primer with Example Use Cases. Disponível em <www.smartcardalliance.org > acessado em 28 de abril 2015.

BLUETOOTH DEVELOPER PORTAL. Bluetooth Smart (Low Energy) Technology. Disponível em <https://developer.bluetooth.org/TechnologyOverview/Pages/BLE.aspx> acessado em 1 de maio 2015.

SUPEALA, D. Testing in the park: real-time simulation of our Smart Public Transport project. Disponível em <http://www.onyxbeacon.com/blog> acessado em 1 de maio 2015. 